\title{
A HISTORY OF THE TREATMENT OF TRIGEMINAL NEURALGIA
}

\author{
By Wilfred HARRIS, M.D. \\ Consulting Physician St. Mary's Hospital and Maida Vale Hospital
}

Neglecting the ancient writings of Galen and Avicenna, and the legends concerning Bishop Button in the $13^{\text {th }}$ century at Wells Cathedral, trigeminal neuralgia was scarcely recognised as a special entity apart from other pains about the face and head, or from clonic facial spasm, until the middle of the 18 th century, when Nicolaus André called it 'Tic Douloureux.' It was not until Sir Charles Bell, in 1820 , differentiated the motor seventh nerve, the portia dura, from the sensory portion of the trigeminal nerve, that surgery began to play a more scientific part in the treatment of the disease, for previously division of the facial nerve had frequently been done for painful spasms of the face. It is true that in 1748 Schlichting had divided the infraorbital nerve for facial neuralgia, with very little success. In I773 John Fothergill described tic douloureux when writing in his Medical Observations and Inquiries ' Of a Painful Affection of the Face,' mentioning that he had seen I4 cases in his lifetime. He used to treat the neuralgia with hemlock (conium), but did not understand the pathology of the disease, ascribing it to ' a cancerous acrimony.' In 1820 Benjamin Hutchinson published a pamphlet on ' Neuralgia Spasmodica,' with a second edition in 1822 , in which he claimed to have observed 200 cases, and to have had considerable success in treatment with large doses of carbonate of iron. During the early igth century, after tic douloureux had been definitely pinned on to the trigeminal nerve, numerous operations on its peripheral branches were undertaken, by neurotomy, neurectomy, and nerve stretchings, chiefly of the infra- and supraorbital branches, and the mental termination of the inferior dental nerve. After the introduction of open anaesthesia by ether, nitrous oxide, and chloroform, Patruban in Germany, in 1853 , divided the maxillary nerve behind the orbit by passing a tenotome along the floor of the orbit, and cutting the nerve as far back as possible, and in $185^{8}$ Carnochan (Amer. F. Med. Sci.) recommended excision of the maxillary nerve with Meckel's ganglion, and Chavasse modified this by extending the area of operation to division of the nerve at the foramen rotundum. When the pain involved the lower jaw only, a favourite operation was $t \delta 5$ trephine the mandible at the level of the middle of the zygoma, after removal of the molar teeth chip away the roof of the inferior dental canahy and, taking care to avoid injuring the inferio dental artery, draw out the nerve and excise $\mathbb{E}$ portion. Pancoast and Salzer in 1872 (Philad. Med. Times) attempted to expose the foramen ovale from below, and later, to divide both the second and third divisions at the foramen oval $\vec{e}$ and $f$. rotundum. Previously ligature of the carotid had been recommended by Nussbaum and Patruban published a series of such cases in 1876 (Allg. Wien Med. Zeit., 42 I).

The results of nearly all these operations we disappointing, and recurrences of pain wegte common in less than six months, or possibly th years. It became realized that repair of the divided nerves depended on new nerve fibres growing down from the Gasserian ganglion, ans the first real attempt to prevent this happening was undertaken by William Rose in March, 1890 ? at King's College Hospital (Lancet, 2, 914). The patient was a woman, with very severe intractable neuralgia, whose lingual and inferior dental nerves: had previously been cut, with only short reliefo Rose first excised the maxilla, and then working: upwards was able to define the foramen ovale above, and fitting the pin of a trephine in the centre of the foramen he cut out a circular pieces of bone from the base of the sphenoid, exposing the under-surface of the ganglion. This he then loosened by passing an aneurysm needle beneatlo it, and he then removed the ganglion piecemeal by using a probe-pointed knife and fine hooked for $\mathrm{N}$ ceps. Probably the whole of the ganglion was not removed, as there was very little harmorrhage, and seven months later the trigeminal anaesthesia was not complete. Victor Horsley had proved by careful dissection that any attempt to strip up the uppe surface of the ganglion from the cavernous sinus invariably tore the wall of that cavity, and that complete removal was therefore impossible ${ }^{-}$ Though the patient did well, the eye was los from keratitis, as the only precaution taken wasp 
the placing of a soft pad over the eye, which no doubt hastened the corneal damage. David Ferrier examined this patient carefully seven months after the operation, and found circumscribed anaesthesia of the right cheek and wasting of the masticatory muscles, and loss of taste on that side of the tongue, with no return of the neuralgia. In December of the same year, I890, Horsley avulsed the sensory root of the trigeminal nerve behind the ganglion in another patient by gently pulling it from the pons, thus preceding Spiller's operation by ten years, but as his patient died seven hours later he gave up this method and reverted to gasserectomy; he generally put a stitch through the eyelids so as to protect the cornea for the first week.

In America Hartley, of New York, in August, i 89 I (N.Y. Med. F., March, I892) made a temporal approach to the ganglion in a man of 46 , opening the skull, and dividing the maxillary and mandibular nerves intracranially at their foramina, and also close to the gasserian ganglion, cutting out the pieces, and pushing down the peripheral ends through their foramina, then loosening the ganglion from the superior wall of the cave of Meckel, with a very small spoon, and then (he said) removing the ganglion completely. Krause, in Germany, six months later (Arch. f. Klin. Chir. $B d$., 34, 821, October, I892) published precisely the same method of operation with partial gasserectomy. During the nineties modified gasserectomy was the operation of choice, though many surgeons in attempting to remove the whole ganglion found that haemorrhage obscured the field of operation, and got bad results. It was about this time that Horsley first used his method of controlling haemorrhage by cutting a fresh piece from the temporal muscle, and pressing it firmly on the source of bleeding. The writer well remembers assisting Horsley in 1895 at the National Hospital during a gasserectomy operation, when he left the wound completely open, saying these operations always went septic, and he then dusted it freely with iodoform before covering it with wool and bandages. The man recovered well.

Jonathan Hutchinson, jun.,* did his first gasserectomy in 1897 , and he purposely left the inner portion of the ganglion in his subsequent operations as he had found there was no anaesthesia of the ophthalmic area, and yet the neuralgia appeared to be cured. This operation eliminates the risk of keratitis, but in some of these cases the sensation may return to a great extent, with recurrence of the neuralgia, even many years later, or the pain may spread to the first division. The writer saw

* 'The Surgical Treatment of Facial Neuralgia,' John Bale \& Danielsson, 1950. last March a lady of 75 in Capetown, with a recent recurrence of the neuralgia, whom Hutchinson had operated on in 1921,28 years previously, very slight anaesthesia remaining.

In 1900 Harvey Cushing, of Baltimore, published a new method of temporal approach to the ganglion (F.A.M.A., 34, 1035) in which he kept the skin incision further back within the hair line, so as to avoid the frequent injury to the upper branch of the facial nerve, and after resecting the zygoma, which caused much of the deformity from wasting of the masticatory muscles, he opened the skull below the arch of the middle meningeal artery, thus requiring less upward compression of the temporal lobe. His operation was closely similar to that described by Poirier in Paris three years previously (Bull. et Mém. Soc. de Chir. de Paris, I 896, n.s. 22, 574-583).

All these operations at this period, and until I92 I, when Frazier (F.A.M.A., 76, I07) published his method of saving the motor trigeminal root, involved wasting of the masticatory muscles, with its consequent deformity. Frazier dissected this bundle from beneath the mandibular nerve at its exit from beneath the ganglion, stimulating the fibres electrically. In I90I Spiller and Frazier (Philad. Med. F., 8, 1059) described their method of dividing the sensory root behind the ganglion, as they had found by experimental work that no regeneration of the proximal fibres took place. This operation proved much easier than that of attacking the ganglion itself, and there is much less haemorrhage. Though it had been his regular practice since 1915, it was not until 1925 that Frazier (Arch. Neur. $\odot$ Psych., 13, 378) published his method of sub-total or fractional resection of the sensory root, so as to spare the ophthalmic fibres, by dividing only the outer two-thirds of the root close behind the ganglion (see f.A.M.A., I93 $1,96,913)$. This has ever since been the basic operation for major trigeminal neuralgia, though others, such as Stookey (Annals of Surg., 1928, 87, 172-78) have practised differential section of the sensory root of its three main divisions, and have stated that section of only a small portion of the outer fibres will abolish the neuralgia, avoiding all risk to the eye, and causing very little anaesthesia of the face.

In 1925 also, Dandy (Fohns Hopkins Bull., Baltimore, 36, 105), who had succeeded Cushing, devised a fresh method of approach to the sensory root by the sub-occipital route, lifting the cerebellar hemisphere, and severing the lower half of the root fibres close to the pons. He claimed that this portion of the root contained especially the pain fibres, and that such section cured the neuralgia, with very little facial anaesthesia, and no risk to the eye. Loyal Davis and Haven (Arch. 
Neur. $\mathscr{E}^{\circ}$ Psych., 1933, 29, I), in their studies of the sensory root, find no evidence of any such topographic arrangement of the fibres, and are of opinion that there is no physiological foundation for any operations aimed at differential interruption of certain functions by partial section near the brain stem. They found that the ophthalmic fibres enter the pons in the inferior and medial position, while the mandibular fibres occupy the superior and lateral position, the maxillary fibres being intermediate.

In 1932 Dandy had done his operation on $25^{\circ}$ cases (Annals of Surg., 96, 787) and he stated that he found the operation much easier than by the temporal route, and usually took only half an hour, the motor root never being injured. In his last I 50 cases he had had no death. Exum Walker, of Atlanta, Georgia (Four. of Neur. E Psych., London, May, 1950), further elaborates Dandy's method, and claims cures with practically no anaesthesia, and even with preservation of the corneal reflex. Personally I cannot but believe that many of these cases will ultimately develop recurrences of the neuralgia, even though they may remain free for ten to twenty years.

With all these improvements in technique, including the sitting-up position, operating under local anaesthesia, and with illuminated retractors, the death rate has fallen steadily from 22.5 per cent. in 1895 to 3.5 per cent. in 1909 , and in Cushing's and Frazier's latest series to 0.2 per cent.

In spite of these excellent results a certain proportion of the cures (7-10 per cent.) develop, after a few weeks or months, troublesome paraesthesiae, on the operated side of the face, that may be called trigeminal causalgia. This is a persistent burning, drawing, or pulling sensation, with slight shoots of pain, mostly around the eye and cheek, causing considerable worry and depression. It is only those cases of sensory root resection, or gasserian destruction from surgical operation or from gasserian alcohol injections that suffer thus. Those cases in which the nerve branches only are cut, in front of the ganglion, either intracranially or externally, do not develop these paraesthesiae. On this account there is a tendency for some surgeons to revert to the original Hartley method of dividing the maxillary and mandibular branches intracranially, and also coagulating both the cut ends electrically, then pushing the peripheral ends down through the foramen rotundum and ovale.

It remains to be seen, as the result of experience, whether electric coagulation prevents nerve regeneration better than filling the foramina with gold leaf, rubber tissue, or other aseptic materials, which have previously been tried.

\section{Medullary Tractotomy}

In 1938 Sjöqvist, of Stockholm, published new method of differential section of the pain fibres in the trigeminal nerve (Zbl. Neurochir.; 2, 274) and, in English (Acta Psych. \& Neu䆑 suppl. xvii). Many workers had for years comf to the conclusion that the pain fibres were minute in size in comparison with touch fibres, an although the facts appear to show, as alread stated, that there is no differentiation in the्ट arrangement of these fibres in the trigeminal roofe between the ganglion and their entry into the pons, yet such differentiation does take place within the pons, the tactile fibres ending in the principal sensory nucleus, while the finer pain and temperature fibres turn downwards into the descending spinal root. Further differential analysis of this tract seems to prove that the ophthalmic, maxillary and mandibular fibres rum separately, the ophthalmic fibres lying deepest. and traceable as low as the second cervical leve $\mathrm{P}^{\circ}$ while the mandibular fibres lie most dorsal, and terminate the highest, the maxillary fibres lying between the other two groups.

By a sub-cerebellar operation the cerebella tonsil is elevated, exposing the side of the medulla, and an incision is made immediately outside the dorsal nuclei, at a point 8-ro ming above the inferior angle of the fourth ventrige, and prolonged laterally $4 \mathrm{~mm}$. to a point $\mathrm{I} \mathrm{mmon}$ above the vagus rootlets. These should not be touched. The depth of the incision should be $3 \mathrm{~mm}$. Olivecrona advises that the incision shoul not be made higher than the inferior angle of the fourth ventricle, in order to avoid risk of vagus $\overrightarrow{\vec{s}}$ palsy, and ataxy from injury to the restiform body? The posterior inferior cerebellar artery is also danger to avoid. Good results of complete facias? hemianalgesia and thermanaesthesia have bees obtained, and the absence of tactile anaesthesia and consequent numbness is a very great gain 3 Pressure pain is also lost.

The operation is just as useless as sensory roo resection in attempting to relieve the paraesthesiae or atypical neuralgia that may follow gasseriap operations or injections, or spontaneous atypicat neuralgia. It also fails to relieve post-herpetie. trigeminal pains. It is perhaps specially indicated in cases of bilateral trigeminal tic, particularlyc when one side has been operated upon with the production of motor fifth paralysis.

Mesencephalic Tractotomy
This was first recommended by Dogliotti is 1938 (Anaesth. \& Anolg., 17, 143-45), and later by Earl Walker (Arch. Neur. E $\mathcal{O}^{\circ}$ Psych. 1942 48, 865), and by Guiot and Farjaz in 1947 (Rerल Neurol., 79, 733). By this method the mediar 
and trigeminal fillets may be divided after the fibres have crossed to the opposite side, the incision being made slightly below the inferior colliculus. This is a neuronic stage higher for the trigeminal fibres and for the spino-thalamic tract, and may prove of value in post-herpetic trigeminal neuralgia, and the paraesthesiae that may follow root section or gasserian injection, in which medullary tractotomy fails to relieve.

Yet a stage further is attempted in the most obstinate cases by prefrontal lobotomy, or topectomy, by Freeman and Watts of the George Washington University (Lancet, 1946, i, 953-55), and by Pool of the New York Neurological Institute, and by le Beau of Paris (Semaine de Hop. Paris, August II, 1948, 24). This is a more severe operation than leucotomy, but probably more precise, and without danger of serious haemorrhage. In either case there is likely to be some evidence afterwards of slight mental deterioration and irresponsibility.

\section{Alcohol Injection}

In I9OI-02 Abadie and Verger, working in Pitres' clinic (Soc. de Med. et de Chir. Bordeaux, I902, pp. 59 and 9I), used cocaine subcutaneously into the areas affected by trigeminal neuralgia, and later followed by subcutaneous injections of alcohol. In r903 Schlösser, a Munich oculist (Zeit. f. Augenheilk., ro, 335), published his method of alcohol injections into the peripheral branches of sensory and motor nerves. For the face he used the intra-oral approach through the soft palate to reach the foramen ovale and rotundum, injecting 80 per cent. alcohol into the nerve trunks, and got very good results, in some cases relieving the pain for years. He taught Ostwalt, of Paris, and then Sicard, and Levy and Baudouin in Paris improved the method by using the lateral approach to the two foramina externally through the sigmoid notch, and in front of the coronoid process of the mandible. Patrick, in Chicago, and many others in America carried on, but the cures were mostly temporary, the relief lasting from six months to two years before regeneration of the damaged fibres took place. Subsequent injections were usually more difficult on each occasion owing to the formation of dense fibrous tissue, and the temporal intracranial operation was made more difficult, after injections to the foramen ovale, by the formation of meningeal adhesions around the sensory root and ganglion.

In 1910 W. Harris first injected the gasserian ganglion through the foramen ovale, using the lateral route (Lancet, 1912, i, 218). This was probably the first peimanent cure by injection, the patient, a man, living another 27 years with no recurrence of neuralgia.

Härtel used the anterior route in front of the coronoid proceśs, giving a steeper line of approach to the foramen ovale, and applied it to the treatment of trigeminal neuralgia (Deut. Zeit. Chir., I914, 126, 429). Harris has since shown that this method of gasserian injection is also applicable to the intractable migraines and ciliary neuralgias, and to unilateral post-traumatic headaches, and trigeminal tic in disseminated sclerosis (Brit. Med. F., 1936, 1946, and 1950).

\section{HOW TO GET THERE}

An Address Book for the Medical profession, showing how to reach the various Colleges, Societies, Institutes and Hospitals in and near London. Third edition : 1950 .

Published by the

FELLOWSHIP OF POSTGRADUATE MEDICINE

I Wimpole Street, London, W. I

Price 2s. 6d. 